\title{
Internet Addiction, Depression, Anxiety and Stress among Indian Youth
}

Pragya Lodha

Masters in Clinical Psychology, Maniben Nanavati Women's College, Mumbai.

Corresponding author: Pragya Lodha

Email-pragya6lodha@gmail.com

\begin{abstract}
Background and Objectives: The phenomenon of internet addiction has grown to be one of the most discussed and clinically implicated areas in research for the last decade. The aim of this study was to determine the level of internet addiction among youth and its relation to depression, anxiety and / or stress among the Indian youth.

Methods: The sample for this study was 349 male and female participants between the age group of 15-29 years, across various cities in India. Convenient sampling and snowball sampling methods were engendered for the purpose of collecting data. The Internet Addiction Test (IAT) by Kimberley Young and the Depression Anxiety and Stress Scale- 21 (DASS- 21) by Lovibond and Lovibond was administered to the sample. A two-way MANOVA was used to analyse the data of this study.

Results: Results showed that all findings for Wilk's Lambda and Pillai's Trace assessing the relationship between internet addiction and gender with depression, anxiety and stress were non-significant.

Conclusion: The findings suggest that there is a relationship between internet addiction, depression, anxiety and stress. However, the findings of this study suggest that there is no significant relationship between internet addiction and gender with depression, anxiety and / or stress among Indian youth.
\end{abstract}

Keywords: Internet addiction, depression, anxiety, stress, Indian youth.

(Paper received $-9^{\text {th }}$ December 2018, Peer review completed $-20^{\text {th }}$ December 2018)

(Accepted $-24^{\text {th }}$ December 2018)

\section{INTRODUCTION}

Internet Addiction is defined as the excessive use of internet; any online-related, compulsive behaviour which interferes with normal living and causes severe stress on family, friends, loved ones, and one's work environment [1]. It is a real problem expanding across the globe. Though there is no criterion for classifying it as a disorder, internet addiction is a problematic behavioural addiction among the youth that has led to severally proposed negative bio-psycho-social outcomes for them. Among the various negative outcomesincreased levels of stress, and higher rates of depression and anxiety have been found and confirmed by several studies and mental health professionals across the globe [2-5]. In India, where approximately 20-30\% of the population has access to the internet, approximately $70 \%$ are young users. Research has indicated that there has been a surge by $14 \%$ in the number of internet users in India. Among the total of approximately 375 million users of internet, more than 120 million users are youth with median age less than 28 years [6]. Addictive use of the internet includes the use of computers and smartphones, involving-

1. Internet overuse (surfing / gambling / shopping / gaming)

2. Excessive use of social media sites- Facebook, Instagram, Whatsapp, Snapchat, Tinder and Twitter

3. Over access to online pornography

4. Online shopping addiction 


\section{Internet Addiction}

The Internet is the global system of interconnected computer networks that use the internet protocol suite (Transmission Control Protocol/Internet Protocol, TCP/IP) to link devices worldwide. It is a network of networks that consists of private, public, academic, business, and government networks of local to global scope, linked by a broad array of electronic, wireless, and optical networking technologies.

There's almost no limit to what one can do online. The Internet makes it possible to quickly find information, communicate with people around the world, manage day to day activities, stream into online media and engage in myriad other activities.

It was the late 1960s and earlier 70s when the internet (ARPANET) was being developed, and it was till 1995 , that the internet users were less than $1 \%$. However, with time, the internet users have grown to cross the number of 3.8 billion users (and still growing) with a penetration rate of $51 \%$. Asians make half of the internet users in the world [7]. While the global Internet users' growth rate remained flat at $10 \%$, Internet user numbers in India grew more than $28 \%$ to 355 million users until mid-2016 [8]. Presently, India ranks as the second largest consumer of internet (after China) with 462.1 million users and the internet penetration percentage reaching to $34.1 \%$ of the population in India [7].

To further understand the usage of internet in India, the same can be bifurcated on the basis of gender-based use of internet and demography-wise internet usage [9]. The penetration of internet seen in the urban-rural divide is vast with 59\% penetration in urban Indian and only $19 \%$ in rural India. Among urban internet users in India, $51 \%$ and more of internet users are using internet on a daily basis that is at least once a day [9]. Whereas, $48 \%$ and more of internet users of rural India are using the internet on a daily basis [9]. The user demographics can further be divided into users being- school going children, young men, college students, working and non-working women and older men.

The gender ratio for internet use reveals that approximately $60 \%$ users are male and $40 \%$ users are female in urban India, however, the ratios are much more discrepant when it comes to rural India. Only $25 \%$ users make up females using internet as opposed to a humongous $75 \%$ of male users [9-10].

Internet use is also understood with the underlying purpose of internet among the rural and urban internet users. Where $69 \%$ and $68 \%$ (making up the maximum users) of users in urban India use the internet for online communication and social networking; only 39\% and 31\% (making up the maximum users) of internet users in rural India use internet for entertainment and social networking [11].

In Rural India, $80 \%$ of non-users are not aware of the benefits of internet and $20 \%$ don't feel the need for internet. Surprisingly, even in Urban India, 76\% non-users reported not being aware of the benefits on Internet. Consequently, 99\% of non-users are non-committal towards adopting internet in the coming days. It is interesting to note that in both Urban and Rural India, 'lack of means' (including affordability and other factors) are not that critical a factor for the non-users [9].

Indians spend the most time on Android phones, spending nearly 150 billion hours between 2014-2016 [8]. On an average, Indian consumers spend as much as 28 hours a week on their smartphones, seven-fold more than the time they end up spending in watching programmes on television, as more users access internet on their mobile phone; around 4\% of the time is spent online shopping [12]. By June 2017, it was estimated that adults in India will spend an average of 1 hour and 18 minutes daily with digital media as compared to adults in Japan and South Korea who will roughly spend 3 hours 5 minutes and 3 hours 26 minutes, respectively, according to eMarketer's forecast on time spent with media. Adults' average time spent per day with digital media will grow $14.4 \%$ this year, with much of that spurred by rural populations gaining internet access for the first time. Adults in India are expected to spend 34 minutes with smartphones in 2017, an increase of $23.1 \%$ from 2016 [11]. By 2021, there will be about 635.8 million users of internet in India [6].

Internet Addiction, is alternatively also called 'excessive internet use (EIU)', 'problematic internet use (PIU)', 'dysfunctional internet use (DIU)', 'pathological internet use', 'internet overuse' or 'compulsive internet use (CIU)'. Internet addiction as defined by Kimberley Young, is any online-related, compulsive behaviour which interferes with normal living and causes severe stress on family, friends, loved ones, and one's work environment. Internet addiction has been called Internet dependency and Internet compulsivity. By any name, it is a compulsive behaviour that completely dominates the addict's life. Internet addicts make the Internet a priority more important than family, friends, and work. The Internet becomes the organizing principle of addicts' lives [13]. 
Addiction to the internet has several implications on the physiological and psychological well-being of the user. Excessive use may result in various psychiatric and medical conditions.

\section{Internet Addiction and Depression}

Does the Internet cause the mental illness, or does mental illness lead people to abuse the Internet? Researcher tried to answer that question in a 1998 study by providing Internet access to 169 people who previously had not been able to log on from home. The researchers reported in American Psychologist that the more time these people spent online, the less time they spent with their families, the smaller their social circles became and the more depressed and lonely they felt. The research stated that even for people who don't manifest addictive behaviour, the Internet is almost an invitation to obsession, compulsive use and various other psychopathological determinant behaviour [1].

Internet addiction and depression have a bidirectional relationship, as opposed to a directive one. Youth suffering from depression are more prone to spend more time on the internet [14-16] and vice versa, those involved in excessive use of the internet are more likely to be depressed [4-5, 17-18]. It must also be understood that there is no cause and effect relationship between the two variables and simply that the risk for the other variable increases in the presence of the former variable.

Excessive engagement in virtual social functions is linked to psychological disorders like depression and addiction [19]. This phenomenon is more widely studied and understood in the younger population whose lives are turning global. From smartphones, tablets, computers / laptops and kindle- youth is spending more time on the internet to communicate, entertain, learn, share and express. Thus, the likelihood of problematic use among this population is greater. One common observation seen in many excessive internet users (or problematic internet users) is depression [20]. People addicted to the internet replace real, humane relationships with virtual, online relationships and this impacts their mental well-being and mental health. Young [1] reported that the vast majority of Internet addicts have a history of depression and anxiety. Low self-esteem has also been reported by several researchers [21-23]. The time they spend using the Internet makes them isolated from others while increasing their level of depression itself, eventually leading the adolescent to experience a never-ending cycle of depression. In understanding the relationships between internet addiction and depression, the following possibilities must also be considered -

1. The individual is likely to have low self esteem

2. The individual is likely to have poor social, familial and peer support that leads them to seek appreciation, approval and recognition / validation on the internet

3. The individual may have history of depression and is therefore likely to isolate self and may want to reach out for help through social media. This may lead to excessive engagement as a means of maintaining virtual relationships while escaping the real ones

4. Internet access may be easy and pervasive

5. Few integral factors such as low self-esteem, weakened motivation, a sense of insecurity, fear of rejection, need for endorsement as linked with depression are believed to be the most influential factors contributing Internet usage

6. Internet addiction may act as mask for depression seen in younger populations [22].

\section{Internet Addiction and Anxiety}

People with internet addiction show their anxiety by various modes of operation such as checking emails in mid-night after suddenly waking from sleep or the connecting to the Internet first thing in the morning. The perceived detachment from reality, inadequate sleep, persistent anxiety of not being online for hours, social isolation, and occupational dysfunctional condition all lead the individual to experience a sense of extreme depression. The irony of this problem is similar to other sorts of depression, the individual will depend on the Internet itself to get a relief from this stress, anxiety and depression, resulting in more depression, anxiety and stress as well. The vicious cycle continues.

Panic disorder, generalized anxiety and social anxiety [24-25] have widely been studied as comorbid psychiatric conditions in individuals involved with excessive internet use [26-29].

There exists a positive and significant correlation between the level of anxiety and internet addiction [30]. Problematic internet use may serve to worsen to social fears and avoidance to face the social interactions 
[31]. Adolescents with internet addiction showed reduce functional connectivity spanning distributed network [32]. There is also found a significant relationship between anxiety and depression in childhood with internet addiction in adolescent. Clinicians should consider anxiety during childhood to prevent internet addiction [33]. Studies have also established that anxiety can significantly predict internet addiction [29].

People addicted to alcohol, cigarettes, drugs, food, and / or sex have a higher risk of developing IA, because they have learned to deal with anxiety and difficulties through compulsive behaviour [34].

In addition, the concept of FOMO or Fear of Missing Out is also discussed in adjunct to the anxiety related to missing out on information on social / digital media which invariably develops a compulsion to check the phone for notifications. A similar relationship exists in association with anxiety problems as well.

\section{Internet Addiction and Stress}

Psychological factors like loneliness, low self-esteem, poor coping capacity, anxiety, stress, depression and aggressive behaviour are also present in individuals, along with internet addiction [35]. Studies highlight that Internet Addiction causes damage in social, physical, and mental aspects of life, generating job loss, divorce, family disagreements, social isolation, academic failure, abandonment or expulsion from school, insomnia, musculoskeletal pain, tension headaches, malnutrition, fatigue, and blurred vision and cognitive impairments like inattention, difficulty concentrating, procrastination, and incomplete tasks [27]. Higher usage for social purposes correlated with increased smartphone user stress.

Using the internet can lead to lower attention span and make it more difficult to read in the traditional sense [36]. Social networking could be potentially harmful to the people [37]. Social networks are the true downfall for people who use the internet [38]. In accordance with development of substance-related disorders, behavioural addictions, such as internet use disorders and pathological gambling are regarded as repetitive excessive behaviour which increasingly turns into an automatic action which is difficult to control intentionally [39]. Excessive use of internet also effects the academic achievements of students. Students addicted to internet are more involved in it than their studies. So, they have poor academic performance [40]. With all these conditions on the rise, stress levels are bound to increase on a bio-psycho-social level. People with mental disorders or symptoms as depression, feelings of isolation, stress or anxiety, may "selfmedicate" by using the Internet in the same way that some people use alcohol or abuse drugs to selfmedicate the symptoms of their mental disorder. This reinforces the levels of stress and moves an individual away from well being. Thus, a bidirectional relationship also exists between internet addiction and stress.

\section{METHODOLOGY}

\section{Research Question}

The following were the research questions for the study:

1. Is internet addiction in young males and females associated with symptoms of depression, anxiety and / or stress?

2. Are there gender differences in internet addiction patterns among the youth?

Aim

To determine the level of internet addiction among youth and its relation to depression, anxiety and / or stress.

\section{Objectives}

The following were the objectives for the study:

1. To ascertain the difference between participants with high internet addiction and participants with low internet addiction on depression scores of DASS 21.

2. To ascertain the difference between participants with high internet addiction and participants with low internet addiction on anxiety scores of DASS 21. 
3. To ascertain the difference between participants with high internet addiction and participants with low internet addiction on stress scores of DASS 21.

4. To ascertain the gender differences on internet addiction among youth.

\section{Hypotheses}

The following were the hypotheses for the study:

i. Females with high Internet Addiction scores will have higher scores on depression than females with low Internet Addiction scores.

ii. Females with high Internet Addiction scores will have higher scores on anxiety than females with low Internet Addiction scores.

iii. Females with high Internet Addiction scores will have higher scores on stress than females with low Internet Addiction scores.

iv. Males with high Internet Addiction scores will have high scores on depression than males with low Internet Addiction scores.

v. Males with high Internet Addiction scores will have high scores on anxiety than males with low Internet Addiction scores.

vi. Males with high Internet Addiction scores will have high scores on stress than males with low Internet Addiction scores.

vii. Males with high Internet Addiction scores will have higher scores on depression than Females with high Internet Addiction scores.

viii. Males with high Internet Addiction scores will have higher scores on anxiety than Females with high Internet Addiction scores.

ix. Males with high Internet Addiction scores will have higher scores on stress than Females with high Internet Addiction scores.

x. Males will have a higher score on Internet Addiction Test than Females.

\section{Independent Variables (IV):}

The IV i.e., Internet Addiction with two levels-

A. Internet Addiction

i. High Internet Addiction score

ii. Low Internet Addiction score

B. Gender

i. Males

ii. Females

\section{Dependent Variables (DV):}

The DV i.e., the score obtained on DASS 21 with three levels-

1. Depression

2. Stress

3. Anxiety

\section{Operational Definition:}

1. Internet Addiction - The high and low score of internet addiction as obtained on Internet Addiction Test (IAT) by the young males and young females on whom the IAT would be administered across urban cities of India.

2. Gender - The state of being either male or female in a socio-cultural context across urban cities of India.

3. Depression - The score of depression as obtained on Depression Anxiety Stress Scale 21 (DASS 21) on items $3,5,10,13,16,17$ and 21 by the young males and young females.

4. Anxiety - The score of anxiety as obtained on DASS 21 on items $2,4,7,9,15,19$ and 20 by the young males and young females. 
5. Stress - The score of stress as obtained on DASS 21 on items $1,6,8,11,12,14$ and 18 by the young males and young females.

\section{Participants}

The sample consisted of young males and young females within the age range of $15-29$ years $(M=20 \pm 2.87)$ in this study, with a criterion of age selected according to the 12th Fifth Year Plan of India (Vol. II, 2013). The participants were from urban cities across India. All participants had access to internet and had completed a minimum education up-to VIII grade and knew English.

\section{Sample Size}

The sample size was $482(\mathrm{n}=482)$ with 179 males and 303 females. However, the sample was filtered to a total of 349 (males $=174$, females $=175$ ) after excluding outliers. Outliers included-participants who did not qualify for the age range, were non-Indian national survey respondents, submitted incomplete physical forms and those who scored 39 (median split value for Internet Addiction scores) were excluded from the sample.

\section{Inclusion Criterion}

1. Youth (males and females) between the age group of 15-29 years were chosen according to the 12th Fifth Year Plan of India (Vol. II, 2013)

2. Young males and females residing in urban cities across in India.

3. Young males and females who have internet access in these cities (as mentioned above).

\section{Research Design}

A 2 x 2 factorial design was used to study the results of this study.

\begin{tabular}{|l|lll|lll|}
\hline & \multicolumn{3}{l}{ High Internet Addiction } & \multicolumn{3}{c|}{ Low Internet Addiction } \\
\hline Males & $\begin{array}{l}\text { Males with High Internet } \\
\text { Addiction }\end{array}$ & $\begin{array}{l}\text { Males with Low Internet } \\
\text { Addiction }\end{array}$ & \\
\hline Females & $\begin{array}{l}\text { Females with High Internet } \\
\text { Addiction }\end{array}$ & $\begin{array}{l}\text { Females with Low } \\
\text { Addiction }\end{array}$ & Internet \\
\cline { 2 - 5 } & & &
\end{tabular}

\section{Sampling Method}

Mixed sampling methods will be employed in order to collect the data for the purpose of this research study.

1. Snowball Sampling Technique, which is a nonprobability sampling technique was one of the sampling methods where the existing study participants were aid in recruiting future participants from among their acquaintances.

2. Convenient Sampling was used as sampling technique where the participants were selected on the basis of the convenience of reaching out to them for the purpose of this research study. These participants included acquaintances and participants within the known reach of the researcher.

\section{Procedure}

The data for this research study was collected using E-forms as Google forms and physical forms across the major cities of India ensuring that the participants have access to internet and also have a minimal education level up to grade VIII. A prior consent form was sent ensuring anonymity and confidentiality of information which will be used solely for the purpose.

\section{Instrumentation}

1. Internet Addiction Test (IAT): The Internet Addiction Test, developed by Dr. Kimberley S. Young, 1998 [41] is a 20-item scale that measures the presence and severity of Internet dependency among adults. Dr. Kimberly Young, a professor at St. Bonaventure University and director of the Center for Internet Addiction Recovery, developed the IAT to assess symptoms of Internet addiction and compulsivity in a variety of test settings. Overall, the IAT is a valid and reliable instrument that may be used in further research on Internet addiction. Following are the cut offs for IAT - 
- Score between 20 - 49 points: Average online user.

- Score between 50 - 79 points: Occasional or frequent problems because of the Internet.

- Score between $80-100$ points: Internet usage is causing significant problems in your life.

2. Depression, Anxiety, Stress Scale-21 (DASS-21): The Depression, Anxiety and Stress Scale - 21 Items (DASS-21) is a self-report 4-point Likert scale and composed of three subscales: Depression (DASS-D), Anxiety (DASS-A), and Stress (DASS-S). It was developed by Lovibond and Lovibond, 1995 in the University of New South Wales (Australia). Each of the three DASS-21 scales contains 7 items, divided into subscales with similar content. The depression scale assesses dysphoria, hopelessness, devaluation of life, self-deprecation, lack of interest / involvement, anhedonia and inertia. The anxiety scale assesses autonomic arousal, skeletal muscle effects, situational anxiety, and subjective experience of anxious affect. The stress scale is sensitive to levels of chronic nonspecific arousal. It assesses difficulty relaxing, nervous arousal, and being easily upset / agitated, irritable / over-reactive and impatient. Scores for depression, anxiety and stress are calculated by summing the scores for the relevant items [42].

\section{STATISTICAL ANALYSIS}

Descriptive Statistical Analysis (Range, Mean and Standard Deviation) of the data was performed per variable. A median split was performed for Internet Addiction scores. This study was a 2 x 2 factorial design research, assuming the principles of normality, parametric test was used. A two-way Multivariate Analysis of Variance (MANOVA) for inferential statistical analysis was performed using SPSS version 22, to test the hypotheses.

\section{RESULTS}

Table 1: Statistical Properties of Variables

\begin{tabular}{|l|r|r|r|}
\hline Variable & $\mathbf{N}$ & Mean & SD \\
\hline Age & 349 & 20.00 & 2.878 \\
\hline Internet Addiction & 349 & 39.80 & 16.807 \\
\hline Depression & 349 & 5.98 & 5.090 \\
\hline Anxiety & 349 & 5.33 & 4.324 \\
\hline Stress & 349 & 6.50 & 4.516 \\
\hline
\end{tabular}

The basic statistical properties are explained by Table 1 which were performed on a sample of the 349 participants with a mean age of 20 years $(\mathrm{SD}=2.87)$. The mean value for Internet Addiction as obtained on the Internet Addiction Test was equal to 39.8 ( $\mathrm{SD}=16.8$, explained by the width of range score as 93). Depression, Anxiety and Stress among this population was found with a mean score of- 5.98 (SD = 5.09), $5.33(\mathrm{SD}=4.32)$ and $6.50(\mathrm{SD}=4.51)$ respectively.

The statistical analysis performed on the data showed that sample was normally distributed and fit for performing parametric tests. After establishing the normality of data, a two-way Multivariate Analysis of variance (MANOVA) was performed to analyse the hypotheses in order to study the impact of the two independent variables (IV)- internet addiction and gender on dependent variables (DV)- depression, anxiety and stress.

With reference to Table 2a, the mean score of depression for males with high internet addiction $(N=78)$ is $\mathrm{M}=5.90(\mathrm{SD}=5.57)$ whereas that for males with low internet addiction (96) is $\mathrm{M}=4.99(\mathrm{SD}=4.18)$. The mean score of anxiety for males with high internet addiction $(78)$ is $\mathrm{M}=5.13(\mathrm{SD}=4.09)$ whereas that for 
males with low internet addiction (96) is $\mathrm{M}=4.52(\mathrm{SD}=3.84)$. The mean score of stress for males with high internet addiction $(\mathrm{N}=78)$ is $\mathrm{M}=6.27(\mathrm{SD}=4.57)$ whereas that for males with low internet addiction (96) is $\mathrm{M}=6.04(\mathrm{SD}=4.66)$. Likewise, the mean score of depression for females with high internet addiction $(\mathrm{N}=$ $96)$ is $\mathrm{M}=6.86(\mathrm{SD}=5.09)$ whereas that for females with low internet addiction (79) is $\mathrm{M}=6.19(\mathrm{SD}=5.44)$. The mean score of anxiety for females with high internet addiction (96) is $\mathrm{M}=6.19(\mathrm{SD}=4.76)$ whereas that for females with low internet addiction (79) is $\mathrm{M}=5.46(\mathrm{SD}=4.42)$. The mean score of stress for females with high internet addiction $(\mathrm{N}=96)$ is $\mathrm{M}=7.04(\mathrm{SD}=4.27)$ whereas that for females with low internet addiction (79) is $\mathrm{M}=6.65(\mathrm{SD}=4.57)$.

Table 2a: Statistical Analysis: Internet Addiction and Gender on Depression, Anxiety and Stress

\begin{tabular}{|c|c|c|c|c|c|}
\hline \multicolumn{3}{|c|}{ Variables } & \multirow{2}{*}{$\begin{array}{r}\text { Mean } \\
4.99\end{array}$} & \multirow{2}{*}{$\begin{array}{r}\text { SD } \\
4.189 \\
\end{array}$} & \multirow{2}{*}{$\begin{array}{l}\mathbf{N} \\
96\end{array}$} \\
\hline \multirow[t]{9}{*}{ Depression } & \multirow[t]{3}{*}{ Male } & Low IA & & & \\
\hline & & High IA & 5.90 & 5.570 & 78 \\
\hline & & Total & 5.40 & 4.863 & 174 \\
\hline & \multirow[t]{3}{*}{ Female } & Low IA & 6.19 & 5.449 & 79 \\
\hline & & High IA & 6.86 & 5.098 & 96 \\
\hline & & Total & 6.56 & 5.255 & 175 \\
\hline & \multirow[t]{3}{*}{ Total } & Low IA & 5.53 & 4.822 & 175 \\
\hline & & High IA & 6.43 & 5.321 & 174 \\
\hline & & Total & 5.98 & 5.090 & 349 \\
\hline \multirow[t]{9}{*}{ Anxiety } & \multirow[t]{3}{*}{ Male } & Low IA & 4.52 & 3.842 & 96 \\
\hline & & High IA & 5.13 & 4.094 & 78 \\
\hline & & Total & 4.79 & 3.957 & 174 \\
\hline & \multirow[t]{3}{*}{ Female } & Low IA & 5.46 & 4.420 & 79 \\
\hline & & High IA & 6.19 & 4.760 & 96 \\
\hline & & Total & 5.86 & 4.611 & 175 \\
\hline & \multirow[t]{3}{*}{ Total } & Low IA & 4.94 & 4.127 & 175 \\
\hline & & High IA & 5.71 & 4.493 & 174 \\
\hline & & Total & 5.33 & 4.324 & 349 \\
\hline \multirow[t]{9}{*}{ Stress } & \multirow[t]{3}{*}{ Male } & Low IA & 6.04 & 4.665 & 96 \\
\hline & & High IA & 6.27 & 4.572 & 78 \\
\hline & & Total & 6.14 & 4.612 & 174 \\
\hline & \multirow[t]{3}{*}{ Female } & Low IA & 6.65 & 4.571 & 79 \\
\hline & & High IA & 7.04 & 4.275 & 96 \\
\hline & & Total & 6.86 & 4.403 & 175 \\
\hline & \multirow[t]{3}{*}{ Total } & Low IA & 6.31 & 4.620 & 175 \\
\hline & & High IA & 6.70 & 4.414 & 174 \\
\hline & & Total & 6.50 & 4.516 & 349 \\
\hline
\end{tabular}

Table 2a shows that females with higher scores on internet addiction have higher scores on depression ( $\mathrm{M}=$ $6.86, \mathrm{SD}=5.098)$ anxiety $(\mathrm{M}=6.19, \mathrm{SD}=4.76)$ and stress $(\mathrm{M}=7.04, \mathrm{SD}=4.27)$ than males with higher scores on internet addiction on depression $(\mathrm{M}=5.90 \mathrm{SD}=5.57)$, anxiety $(\mathrm{M}=5.13, \mathrm{SD}=4.09)$ and stress $(\mathrm{M}=6.27$, $\mathrm{SD}=4.57)$.

Overall scores also project that females have higher scores on depression $(\mathrm{M}=6.56, \mathrm{SD}=5.25)$, anxiety $(\mathrm{M}=$ $5.86, \mathrm{SD}=4.61)$ and stress $(\mathrm{M}=6.86, \mathrm{SD}=4.40)$ than males on depression $(\mathrm{M}=5.40, \mathrm{SD}=4.86)$, anxiety $(\mathrm{M}=4.79, \mathrm{SD}=3.59)$ and stress $(6.14, \mathrm{SD}=4.61)$.

Table $2 \mathrm{~b}$ compare the descriptive statistical analysis for males and females on high and low scores of Internet Addiction. Results show that the mean and standard deviation values for males $(\mathrm{N}=79)$ with high internet addiction $(\mathrm{M}=54.15, \mathrm{SD}=10.95)$ is greater than that of females $(\mathrm{N}=98)$ with high internet addiction $(\mathrm{M}=$ 53.06, $\mathrm{SD}=9.93)$. Similarly, the mean and standard deviation values for males $(\mathrm{N}=96)$ with low internet 
addiction $(\mathrm{M}=26.17, \mathrm{SD}=9.62)$ is greater than that of females $(\mathrm{N}=79)$ with low internet addiction $(\mathrm{M}=$ 26.03, $\mathrm{SD}=7.72$ ).

Table 2b: Mean and SD for Internet Addiction and Gender

\begin{tabular}{|l|l|l|l|}
\hline Variable & Sample (N) & Mean & SD \\
\hline Males (High Internet Addiction) & 78 & 54.15 & 10.95 \\
\hline Males (Low Internet Addiction) & 96 & 26.17 & 9.62 \\
\hline Females (High Internet Addiction) & 96 & 53.09 & 9.93 \\
\hline Females (Low Internet Addiction) & 79 & 26.03 & 7.72 \\
\hline
\end{tabular}

Table 3: Multivariate Tests

\begin{tabular}{|c|c|c|c|c|c|c|}
\hline \multicolumn{2}{|c|}{ Effect } & \multirow{2}{*}{\begin{tabular}{|l|} 
Value \\
.704 \\
\end{tabular}} & \multirow{2}{*}{$\begin{array}{c}\mathbf{F} \\
271.610^{\mathrm{b}}\end{array}$} & \multirow{2}{*}{$\begin{array}{r}\text { Hypothesis } \\
\text { df }\end{array}$} & \multirow{2}{*}{$\begin{array}{l}\text { Error df } \\
343.000\end{array}$} & \multirow{2}{*}{$\begin{array}{l}\text { Sig. } \\
.000\end{array}$} \\
\hline Intercept & $\begin{array}{l}\text { Pillai's } \\
\text { Trace }\end{array}$ & & & & & \\
\hline & $\begin{array}{l}\text { Wilks' } \\
\text { Lambda }\end{array}$ & .296 & $271.610^{b}$ & 3.000 & 343.000 & .000 \\
\hline \multirow[t]{2}{*}{ Gender } & $\begin{array}{c}\text { Pillai's } \\
\text { Trace }\end{array}$ & .016 & $1.807^{\mathrm{b}}$ & 3.000 & 343.000 & .146 \\
\hline & $\begin{array}{l}\text { Wilks' } \\
\text { Lambda }\end{array}$ & .984 & $1.807^{\mathrm{b}}$ & 3.000 & 343.000 & .146 \\
\hline \multirow[t]{2}{*}{$\begin{array}{c}\text { Internet } \\
\text { Addiction }\end{array}$} & $\begin{array}{c}\text { Pillai's } \\
\text { Trace }\end{array}$ & .009 & $.985^{\mathrm{b}}$ & 3.000 & 343.000 & .400 \\
\hline & $\begin{array}{l}\text { Wilks' } \\
\text { Lambda }\end{array}$ & .991 & $.985^{b}$ & 3.000 & 343.000 & .400 \\
\hline \multirow{2}{*}{$\begin{array}{l}\text { Gender * } \\
\text { Internet } \\
\text { Addiction }\end{array}$} & $\begin{array}{c}\text { Pillai's } \\
\text { Trace }\end{array}$ & .001 & $.062^{\mathrm{b}}$ & 3.000 & 343.000 & .980 \\
\hline & $\begin{array}{l}\text { Wilks' } \\
\text { Lambda }\end{array}$ & .999 & $.062^{b}$ & 3.000 & 343.000 & .980 \\
\hline
\end{tabular}

As suggested by Table 3, in the case of this study, the value of Wilk's Lambda $(\lambda)$ for Gender $=0.948, F$ $(3,343)=1.807$. The value of Wilk's Lambda $(\lambda)$ for Internet Addiction $=0.991, F(3,343)=0.985$. Similarly, the Wilk's Lambda $(\lambda)$ for the interaction of Internet Addiction and Gender $=0.999, F(3,343)=0.062$. The value for Pillai's Trace for Gender was found at 0.016 , F $(3,343)=1.807$. The value for Pillai's Trace for Internet Addiction $=0.009, \mathrm{~F}(3,343)=0.985$ and the same for the interaction of Internet Addiction and Gender $=0.001, \mathrm{~F}(3,343)=0.062$.

All findings for Wilk's Lambda and Pillai's Trace assessing the relationship between internet addiction and gender with depression, anxiety and stress were non-significant.

Given the significance of overall tests, multivariate tests were performed; all values obtained for the same, were non-significant. As explained by Table 4, the value between subjects' effect for Gender and Depression was found at $F(1,345)=3.958$. Likewise, the between subjects' effect for Gender and Anxiety was found at $F(1,345)=4.651$. and that for Gender and Stress was found at $F(1,345)=2.004$.

Similarly, the value between subjects' effect for Internet Addiction and Depression was found at $\mathrm{F}(1,345)$ $=2.110$. the between subjects' effect for Internet Addiction and Anxiety was found at F $(1,345)=2.098$ and that for Internet Addiction and Stress was found at $F(1,345)=0.411$. The between subjects' effect for the interaction of internet addiction and gender was found at $\mathrm{F}(1,345)=0.046$. 
Table 4: Tests of Between Subjects Effects

\begin{tabular}{|c|c|c|c|c|c|c|}
\hline \multicolumn{2}{|l|}{ Source } & \multirow{2}{*}{$\begin{array}{c}\begin{array}{l}\text { Type III Sum } \\
\text { of Squares }\end{array} \\
173.299^{\mathrm{a}}\end{array}$} & \multirow{2}{*}{$\begin{array}{r}\mathbf{d f} \\
3\end{array}$} & \multirow{2}{*}{\begin{tabular}{|l}
$\begin{array}{l}\text { Mean } \\
\text { Square }\end{array}$ \\
57.766
\end{tabular}} & \multirow{2}{*}{$\begin{array}{c}\mathbf{F} \\
2.254\end{array}$} & \multirow{2}{*}{$\begin{array}{l}\text { Sig. } \\
.082\end{array}$} \\
\hline Corrected & Depression & & & & & \\
\hline $100 \mathrm{cos}$ & Anxiety & $137.866^{b}$ & 3 & 45.955 & 2.489 & .060 \\
\hline & Stress & $54.155^{\mathrm{c}}$ & 3 & 18.052 & .884 & .449 \\
\hline \multirow[t]{3}{*}{ Intercept } & Depression & 12376.778 & 1 & 12376.778 & 482.945 & .000 \\
\hline & Anxiety & 9789.224 & 1 & 9789.224 & 530.277 & .000 \\
\hline & Stress & 14594.530 & 1 & 14594.530 & 714.901 & .000 \\
\hline \multirow[t]{3}{*}{ Gender } & Depression & 101.438 & 1 & 101.438 & 3.958 & .047 \\
\hline & Anxiety & 85.867 & 1 & 85.867 & 4.651 & .032 \\
\hline & Stress & 40.903 & 1 & 40.903 & 2.004 & .158 \\
\hline \multirow{3}{*}{$\begin{array}{l}\text { Internet } \\
\text { Addiction }\end{array}$} & Depression & 54.079 & 1 & 54.079 & 2.110 & .147 \\
\hline & Anxiety & 38.724 & 1 & 38.724 & 2.098 & .148 \\
\hline & Stress & 8.399 & 1 & 8.399 & .411 & .522 \\
\hline \multirow{3}{*}{$\begin{array}{l}\text { Gender * } \\
\text { Internet } \\
\text { Addiction }\end{array}$} & Depression & 1.174 & 1 & 1.174 & .046 & .831 \\
\hline & Anxiety & .334 & 1 & .334 & .018 & .893 \\
\hline & Stress & .613 & 1 & .613 & .030 & .862 \\
\hline \multirow[t]{3}{*}{ Error } & Depression & 8841.561 & 345 & 25.628 & & \\
\hline & Anxiety & 6368.896 & 345 & 18.461 & & \\
\hline & Stress & 7043.089 & 345 & 20.415 & & \\
\hline
\end{tabular}

\section{DISCUSSION}

The aim of this study was to determine the level of internet addiction among Indian youth (15 years to 29 years, males and females) and its relation to depression, anxiety and / or stress. The findings of the sample $(\mathrm{N}=349)$, were analysed and a non-significant relationship between the variables of internet addiction and gender with depression, anxiety and stress, was determined. A nuanced revelation to the findings suggests that individuals with high internet addiction scores did not necessarily (and significantly) relate with higher scores on depression, anxiety or stress. The findings sustained for both the levels of gender- males and females, suggesting that higher scores on internet addiction did not necessarily mean higher scores on depression, anxiety and stress. 
As established, the findings of the study suggest that there are no significant findings with respect to the relationship between internet addiction and depression, anxiety and / or stress in males and females, however, significant mean differences were found in the scores for the similar relationship (internet addiction and gender with depression, anxiety and stress). The analysed data demonstrated that females with high internet addiction had higher scores on depression, anxiety and stress as compared to that of females with low scores on internet addiction. Results also showed that females with high scores on internet addiction had higher scores on depression, anxiety and stress as compared to the scores of males with high scores on internet addiction on depression, anxiety and stress. The finding has been supported as early as in 1996, where is was found that females and more females as homemakers tended to spend more time on the internet as compared to men [43]. Griffiths [44], in a case study, also established a similar finding with females being more addicted to the internet.

Research findings in multitude have evidenced that gender influences the types of applications and underlying reasons for Internet addiction. Men tend to seek out dominance and sexual fantasy online, while women seek out close friendships, romantic partners, and prefer anonymous communication in which to hide their appearance $[1,13,45]$. Men are more likely to become addicted to online games, cyberporn, and online gambling, while women are more likely to become addicted to sexting, testing, social media, eBay, and online shopping. Researchers have demonstrated that females are more likely to be addicted to the internet [46-48]. Gender roles moulded by societal influences harbour gender-normative internet patterns and usage among males and females as best explained with gender-oriented traits [49].

The findings of the present research suggest a non-significant relationship between internet addiction with depression, anxiety and stress. A non-significant relationship is additionally suggested between gender (males and females) and depression, anxiety and stress. In contradistinction, it suggests that higher scores on internet addiction does not necessarily mean higher scores on depression, anxiety and / or stress. However, in retrospection, contrasting to the findings of this study, research literature has multifariously reinforced the relationship of internet addiction with depression, anxiety and / or stress in the non-clinical population [3-4. 50]. However, the current and rampantly pervasive role of internet, especially so in the last 5-7 years has amplified more than double the use than it was before. Thus, internet usage is growing to become a normalised phenomenon and therefore, the terminology of 'excessive internet usage' (that connotes to internet addiction, as suggested by research $[13,51]$ needs revision in the context of prevalent status quo. The present findings of the research contribute to the pool of research literature and data pertaining to internet addiction and its association with psychological (and psychopathological) variables.

A salient consideration while discussing the incidence of internet addiction is that there is no agreed upon definition of internet addiction. Kimberley Young [1] defines internet addiction as "any online-related, compulsive behaviour which interferes with normal living and causes severe stress on family, friends, loved ones, and one's work environment". Nevertheless, there isn't any criterion based on clinical symptoms or duration that may classify internet addiction as a standard phenomenon. However, there has been a proposed internet addiction diagnostic criterion [52]. It consisted of symptom criterion (seven clinical symptoms of Internet Addiction Disorder), clinically significant impairment criterion (functional and psychosocial impairments), course criterion (duration of addiction lasting at least 3 months, with at least 6 hours of non-essential internet usage per day) and exclusion criterion (exclusion of dependency attributed to psychotic disorders). Additionally, access to information and communication technology through cell phones, the internet, and electronic media has increased exponentially around the world [53] and it therefore makes internet use a part and parcel of daily socio-occupational functioning of individuals.

Conclusively, no gold standard of Internet addiction classification exists as 21 different assessment instruments have been identified. They adopt official criteria for substance use disorders or pathological gambling, no or few criteria relevant for an addiction diagnosis, time spent online, or resulting problems. Second, reported prevalence rates differ as a consequence of different assessment tools and cut-offs, ranging from $0.8 \%$ in Italy to $26.7 \%$ in Hong Kong [54]. This demands a deeper elucidation of the concept and occurrence of internet addiction in the present times. Internet addiction has not yet been understood very well, and research on its aetiology and natural history is still in its infancy [55]. 
The Internet Addiction Test given by Kimberley Young was developed in the year, 1998 and despite that it is the most widely used test to study internet addiction, it has not been revised to the present status quo of internet use that may demand a revised criterion for internet addiction. Keeping the definition in mind, it is also essentially required to recognise the novelty in the means of internet use which create a niche in understanding 'internet addiction' as a phenomenon. The internet addiction test is based on the criterion of gambling disorder and retains the theoretical underpinnings of internet addiction dated back to 1998 . However, it is prime to consider the changed patterns of internet availability, internet usage patterns and internet penetration that has inevitably normalised the phenomenon of internet use. This is assisted by Meeker's Report [12] that highlights Indians to be spending the most time on Android phones, spending nearly 150 billion hours between 2014-2016. Mobile accounts for nearly $80 \%$ of web traffic in India, one of the highest globally, only preceded by Nigeria. Various digital-focused government policies like Digital India, Startup India, Jan Dhan Yojana, Aadhaar, Demonetisation and GST Reform also find a mention in the report, adding to the digital engagement. A Bengaluru based news in the Times of India disclosed that Indians, on an average, spend 200 minutes per day on the internet [56]. Moreover, it was found that women were key consumers of digital information. A trend analysis unveiled that Indian digital consumers are marked at a present statistic of 40 million with $64.71 \%$ consumers from urban India [57]. Downloading music, listening to music, buying apparels online, online streaming of videos, playing games online, visiting knowledge-based websites, reading news, reading classified, watching news, visiting cooking websites, watching \& downloading TV series, doing research and watching sports along with visiting matrimony sites are the multitudinous activities that are engaged in by digital consumers [57]. This trend has been shown to have increased among millennial population (youth population). This data further affirms the need to reappraise the concept of internet addiction / excessive internet usage.

With regard to mental health, the internet (and its' use) has had an admonished frame of reference and as previously acknowledged, there is ample mental health literature that has drawn positive correlations between excessive internet use and psychopathological variables such as social isolation, sleep disturbances, loneliness, depression, stress, anxiety and disturbed eating patterns. However, less known are the effects of well-being, happiness and overall happiness in life due to internet use- though findings of positive correlations between internet addiction and these variables have been shown to exist. The relationship between internet addiction and depression, anxiety and stress have both, positive and negative correlations. Studies have either predicted or shown the presence of risk for depression, anxiety and / or stress in relation to internet addiction. These findings have been exponentially true among the younger population (adolescents and young adults).

The present study findings suggest that internet addiction (higher scores, above 39, on internet addiction test) does not significantly correlate with depression, anxiety and / or, stress (higher scores on depression, anxiety and / or stress on DASS 21) and can be further supported by several explanations. Internet penetration rates and internet use has increased every year and considering the changed patterns, there are 50 million internet users that get added on a yearly basis and India may touch a number of 550 million internet users by 2018 [58]. Thus, internet addiction as phenomenon will need to be updated depending on the normal and pathological use of internet with respect to usage. Second in evidence, technological advancements have expanded internet use on several handy devices- computers, laptops, palmtops, smartphones, tablets, iPads, portable Wi-Fis and portable internet hubs and this encourages the use of internet. Thirdly, increasingly, there are greater number of public places that allow, encourage and make available the service of internet- railway stations, cafes, restaurants, shopping malls and various local institutes and public stations. Inadvertently, internet use is promoted. Moving further, work from home and otherwise too, a lot of documentation, filing, billing and payment options are now available online. This option of ease and convenience engages consumers online during their time at work and home. Fifth, there are several work fields these days that require the nature of e-presence of e-tracking that run purely on the basis of internet connection and thus involves the individuals on the internet. Sixth, the internet is an incentivized platform with deals, offers and discounts that attracts people to engage in online activities such as booking, buying and engaging other consumer related activities. And lastly that several daily chores have 
also become online with the advent of internet and therefore engage individuals online for a much longer time than otherwise expected solely for leisure use.

Researchers have found that internet penetration rate is positively correlated with average happiness and that there is a strong positive influence of internet use for younger people [59]. Graham and Nikolova [53] have established that there is a positive relationship between access to technologies like cell phones, TV, and the internet and subjective well-being, around the world using pooled cross-sectional survey data from the Gallup World Poll for 2009-2011. British researchers from the U.K.'s Chartered Institute of IT (known as BCS) have found a link between Internet access and well-being. Overall, the study found that access to the Internet leads people to feel better about their lives (2010). The Pew Research Centre Survey [60] reported that $67 \%$ of respondents felt that internet strengthened their relationships with others. Luxemburgish data extracted from the European Value Survey has also found that evidence that non-users are less satisfied in their life than Internet users [59]. Online activities have also been linked to life satisfaction. Internet adoption and digital users were found to be high on life satisfaction as compared to no users. Additionally, in the study it was also found that internet use was a channel for increasing life satisfaction among weaker groups [61]. Based on 34 years of data collected by the General Social Survey (GSS) on social activities and media usage, it is found that people who are happy report being more active in most social activities, in religion and in newspaper reading [62]. Correlational results of a study done by Leung (2004) showed that internet activities, such as using the Internet for sociability, fun seeking and information seeking, and new media use, correlate positively with various dimensions of social support.

Alternatively, and apart from the fact that internet addiction may not always translate into psychopathological variants, there may be a probable possibility that internet addiction may be a problematic behaviour independent of comorbid symptoms of depression, anxiety and / or stress. As suggested by the findings of the study $(\mathrm{N}=349)$, high scores (above 39) on the internet addiction scale do suggest the presence of internet addiction, however, it does not hold a relation with depression, anxiety and / or stress.

What holds value in the discussion is also to consider that the survey respondents may have had an inherent bias while marking their response to the survey questions ranging from a spectrum of faking good to faking bad. Secondly, it is significant to note that the participants of this youth were largely urban. The cities from where the participants were variable and wasn't controlled for. Thirdly, purpose of internet use was not assessed which also leaves a niche for explaining the patterns of internet use and not just straightforwardly affirm internet addiction. Additionally, what must also be considered is that psychopathological assessment as a prerequisite was not assessed in any of the subjects and that may have led to biased answering on the DASS-21. Fifthly, as an extension to the previous point, there may have been participants who would have been depressed and anxious and possibly internet use rather manage / overcome their symptoms. Sixthly, the sample was circumscribed to merely 349 (original $\mathrm{N}=482$ ) participants and hence the results cannot generalized for the youth. And lastly, it can be proposed that the findings could have been influenced by the vast age range of the youth and probably a shorter age range would have been suggestive of different findings owing to assess a smaller pool of respondents. However, unlikely to most research literature in existence, the present study shows no significant relationship between internet addiction, depression, anxiety and / or stress which holds importance with respect to viewing Internet addiction in a different perspective. Given the present status quo of internet use that conflicts with the proposed definition of internet addiction (implied in the research tool and research literature of this study), internet addiction could be proposed as an independent phenomenon. Implying- it could be independent of co-occurring psychopathological conditions (depression, anxiety and / or stress). These findings can be seen as an alternate extension to the current literature that extensively reinforces the direct relationship between internet addiction and psychopathological variables like depression, anxiety and stress.

Thus, the findings of this study may propose an independent, new model of internet addiction where excessive internet use may not necessarily lead to depression, anxiety or stress. Since the internet is now being used for various purposes, internet usage may also be one of the relief factors from psychopathological symptoms of depression, anxiety and / or stress. Having known the fact that various mental health 
applications and activities can be engaged in online to soothe symptoms of depression, anxiety and / or stress- excessive internet use may actually reduce symptoms of the above proposed psychopathological variables. The findings of the present study contribute a new understanding of internet use ad urges further research to analyse the current patterns of internet use among the youth.

\section{Limitations}

Though findings as discussed above, there are limitations of the study that need to be accounted for and they are as follows:

- The sample size of 349 participants is not representative of the Indian youth and therefore the results cannot be generalized

- The term internet addiction (as defined by Kimberley Young and American Psychiatric Association) is a definition that does not account for the current patterns of internet usage and therefore needs.

- Psychopathological symptomatology in the participants was not assessed before administering the Internet Addiction Test and Depression Anxiety Stress Scale 21.

- Personality characteristics of the participants would also have potentially influenced the responses of the participants and thus confounded the overall responses.

- The methodology for this research employed convenient and snowball sampling instead of randomized sampling which has its inherent bias

- Respondents answering the survey also may have had an inherent bias to answer in a socially desirable manner.

- Demographically, the city of the respondents was not controlled (as e forms were used) which could have influenced the present findings.

\section{Future Scope}

The present study contributes data to suggest that internet addiction may not necessarily be linked to depression, anxiety and / or stress and hold the potential for further exploratory studies. However, the study of a similar nature may assess psychopathology as a prerequisite variable. Future studies may also consider o control variables of age and demographic location. What may importantly be considered is the revised understanding and definition of internet addiction based on the then current internet penetration and usage. The further scope of the present study is also to study a larger population, closer to the representative sample of the age group. The present study can also be expanded to study the internet usage patterns across demographic variants.

\section{CONCLUSION}

The purpose of this study was to examine the relation between internet addiction and gender with depression, anxiety and / or stress. The inferential statistics of two-way MANOVA using the SPSS (version 22) was used to analyse the findings. The findings suggest that there is a relationship between internet addiction, depression, anxiety and stress. However, the findings of this study suggest that there is no significant relationship between internet addiction and gender with depression, anxiety and / or stress among Indian youth.

\section{REFERENCES}

1. Young KS. Internet addiction: The emergence of a new clinical disorder. Cyberpsychol Behav 1998;1(3):23744.

2. Rehman A, Shafi H, Rizvi T. Internet Addiction and Psychological Well-being among Youth of Kashmir. The Int J Indian Psychol 2016;3(3):6-11.

3. Desouky DE, Ibrahem RA. Internet addiction and psychological morbidity among menoufia university students, Egypt. Am J Pub Health Res 2015;3(5):192-8.

4. Al-Hantoushi M, Al-Abdullateef S. Internet addiction among secondary school students in Riyadh city, its prevalence, correlates and relation to depression: A questionnaire survey. Int J Med Sci Public Health. 2014;3(1):10-5 
5. Akin A, Iskender $\mathrm{M}$. Internet addiction and depression, anxiety and stress. Int Online $\mathrm{J}$ Educ Sci 2011;3(1):138-48.

6. The Statistics Portal. (2017). Internet usage in India - Statistics \& Facts [Web log post]. Retrieved from https://www.statista.com/topics/2157/internet-usage-in-india/

7. The Center for Internet Addiction Recovery. (2013). What is Internet Addiction Disorder? Retrieved from http://netaddiction.com/faqs/

8. Zannettou S, Caulfield T, De Cristofaro E, Kourtelris N, Leontiadis I, Sirivianos M, Stringhini G, Blackburn J. The web centipede: understanding how web communities influence each other through the lens of mainstream and alternative news sources. InProceedings of the 2017 Internet Measurement Conference 2017 Nov 1 (pp. 405-417). ACM.

9. Internet IAMAI in India -IMRB Report - 2016 (Rep.). (2016). Retrieved from http://bestmediainfo.com/wpcontent/uploads/2017/03/Internet-in-India-2016.pdf

10. Addiction Help Centre. (2017). How Internet Addiction Affects Your Brain. Retrieved from http://www.addictionhelpcenter.com/how-internet-addiction-affects-your-brain/

11. Young KS, Rogers RC. The relationship between depression and Internet addiction. Cyberpsychol Behav 1998;1(1):25-8.

12. Meeker M. The internet report. HarperCollins Publishers; 1996.

13. Young KS. Treatment outcomes using CBT-IA with Internet-addicted patients. J Behav Addictions 2013;2(4):209-15.

14. Morrison CM, Gore $\mathrm{H}$. The relationship between excessive Internet use and depression: a questionnaire-based study of 1,319 young people and adults. Psychopathology 2010;43(2):121-6.

15. Mythily S, Qiu S, Winslow M. Prevalence and correlates of excessive Internet use among youth in Singapore. Ann Acad Med Singapore 2008;37(1):9-16.

16. Cotton AH. Ensnaring webs and nets: ethical issues in Internet-based research. Contemp Nurse 2004;16(12):114-23.

17. Rabadi L, Ajlouni M, Masannat S, Bataineh S, Batarseh G, Yessin A. The Relationship between Depression and Internet Addiction among University Students in Jordan. J Addict Res Ther 2017;8:6-11.

18. Sharma P, Bharati A, De Sousa A, Shah N. Internet addiction and its association with psychopathology: a study in school children from Mumbai, India. Natl J Community Med. 2016;7(1):2-5.

19. McMillan SJ, Morrison M. Coming of age with the internet: A qualitative exploration of how the internet has become an integral part of young people's lives. New Media \& Society 2006;8(1):73-95.

20. Grohol JM. Too much time online: internet addiction or healthy social interactions?. Cyberpsychol Behav 1999;2(5):395-401.

21. Seabra L, Loureiro M, Pereira H, Monteiro S, Marina Afonso R, Esgalhado G. Relationship Between Internet Addiction and Self-Esteem: Cross-Cultural Study in Portugal and Brazil. Interacting with Computers 2017;29(5):767-78.

22. Bahrainian S, Haji Alizadeh K, Raeisoon M, Hashemi Gorji O, Khazaee A. Relationship of Internet addiction with self-esteem and depression in university students. J Prev Med Hygiene 2014;55(3):86-9.

23. Young KS. Caught in the net: How to recognize the signs of internet addiction--and a winning strategy for recovery. John Wiley \& Sons; 1998

24. Carli V, Durkee T, Wasserman D. The association between pathological Internet use and comorbid psychopathology: a systematic review. Psychopathology 2013;46(1):1-13.

25. Adalier A, Balkan E. The relationship between internet addiction and psychological symptoms. Int J Global Educ 2012;1(2).

26. Younes F, Halawi G, Jabbour H, El Osta N, Karam L, Hajj A, Khabbaz LR. Internet addiction and relationships with insomnia, anxiety, depression, stress and self-esteem in university students: a cross-sectional designed study. PloS One 2016;11(9):e0161126.

27. Santos VA, Freire R, Zugliani M, Cirillo P, Santos HH, Nardi AE, King AL. Treatment of internet addiction with anxiety disorders: Treatment protocol and preliminary before-after results involving pharmacotherapy and modified cognitive behavioral therapy. JMIR Research Protocols. 2016;5(1)e46.

28.

29. Azher M, Khan RB, Salim M, Bilal M, Hussain A, Haseeb M. The relationship between internet addiction and anxiety among students of University of Sargodha. Int J Hum Soc Sci 2014;4(1):288-93.

30. Nima N, Nazanin K. World academy of science, engineering and technology. https://waset.org/Publications/XML?id=1656; 2012.

31. Lee HW, Choi JS, Shin YC, Lee JY, Jung HY, Kwon JS. Impulsivity in internet addiction: a comparison with pathological gambling. Cyberpsychol Behav Soc Network 2012;15(7):373-7.

32. Weinstein A, Dorani D, Elhadif R, Bukovza Y, Yarmulnik A, Dannon P. Internet addiction is associated with social anxiety in young adults. Ann Clin Psychiatry 2015;27(1):4-9.

33. Cho SM, Sung MJ, Shin KM, Lim KY, Shin YM. Does psychopathology in childhood predict internet addiction in male adolescents?. Child Psychiatr Hum Dev 2013;44(4):549-55.

34. Young KS. CBT-IA: The first treatment model for internet addiction. J Cogn Psychother 2011;25(4):304-10.

35. Yen CF, Yen JY, Ko CH. Internet addiction: ongoing research in Asia. World Psychiatry 2010;9(2):97-100.

36. Nalwa K, Anand AP. Internet addiction in students: A cause of concern. Cyberpsychol Behav 2003;6(6):6536.

37. Morozov E. The net delusion: The dark side of Internet freedom. Public Affairs; 2012. 
38. Brock RL, Barry RA, Lawrence E, Dey J, Rolffs J. Internet administration of paper-and-pencil questionnaires used in couple research: assessing psychometric equivalence. Assessment 2012;19(2):226-42.

39. Randler C, Wolfgang L, Matt K, Demirhan E, Horzum MB, Beşoluk Ş. Smartphone addiction proneness in relation to sleep and morningness-eveningness in German adolescents. J Behav Addict 2016;5(3):465-73.

40. Frangos CC, Frangos CC, Sotiropoulos I. A meta-analysis of the reliability of Young's Internet addiction test. In Proceedings of the World Congress on Engineering 2012 (Vol. 1, pp. 368-371).

41. Young K. Internet addiction test (IAT). Stoelting; 2016.

42. Lovibond PF, Lovibond SH. The structure of negative emotional states: Comparison of the Depression Anxiety Stress Scales (DASS) with the Beck Depression and Anxiety Inventories. Behav Res Ther 1995;33(3):335-43.

43. Young KS. Psychology of computer use: XL. Addictive use of the Internet: a case that breaks the stereotype. Psychol Rep 1996;79(3):899-902.

44. Griffiths MD. Internet addiction: an issue for clinical psychology?. Clin Psychol Forum 1996;97:32-6.

45. Bujala A. Gender differences in Internet usage. Act Univers Lodzen Folia Sociolo. 2012;43:49-67.

46. Vaghefi I, Lapointe L, Boudreau- Pinsonneault C. A typology of user liability to IT addiction. Information Systems Journal 2017;27(2):125-69.

47. Carter-Harris L, Ellis RB, Warrick A, Rawl S. Beyond traditional newspaper advertisement: leveraging Facebook-targeted advertisement to recruit long-term smokers for research. J Med Internet Res 2016;18(6).

48. Moore K, McElroy JC. The influence of personality on Facebook usage, wall postings, and regret. Comp Hum Behav 2012;28(1):267-74.

49. Moussavi S, Chatterji S, Verdes E, Tandon A, Patel V, Ustun B. Depression, chronic diseases, and decrements in health: results from the World Health Surveys. The Lancet 2007;370(9590):851-8

50. Gholamian B, Shahnazi H, Hassanzadeh A. The prevalence of internet addiction and its association with depression, anxiety, and stress, among high-school students. Int J Pediatrics 2017;5(4):4763-70.

51. Weinstein A, Lejoyeux M. Internet addiction or excessive internet use. Am J Drug Alcohol Abuse 2010;36(5):277-83

52. Tao R, Huang X, Wang J, Zhang H, Zhang Y, Li M. Proposed diagnostic criteria for internet addiction. Addiction 2010;105(3):556-64.

53. Graham C, Nikolova M. Does access to information technology make people happier? Insights from wellbeing surveys from around the world. The Journal of Socio-Economics 2013;44:126-39.

54. Kuss DJ, Griffiths MD, Binder JF. Internet addiction in students: Prevalence and risk factors. Comp Hum Behav 2013;29(3):959-66.

55. Kuss DJ, Lopez-Fernandez O. Internet addiction and problematic Internet use: A systematic review of clinical research. World J Psychiatry 2016;6(1):143-7.

56. Beard KW, Wolf EM. Modification in the proposed diagnostic criteria for Internet addiction. Cyberpsychol Behav 2001;4(3):377-83.

57. Diwanji P. Be Internet Awesome": Helping kids make smart decisions online. Google. Retrieved July. 2017.

58. American Psychiatric Association. (2016, July). Can You be Addicted to the Internet? [Web log post]. Retrieved from https://www.psychiatry.org/news-room/apa-blogs/apa-blog/2016/07/can-you-be-addictedto-the-internet

59. Pénard T, Poussing N. Usage de l'Internet et investissement en capital social. Recherches économiques de Louvain. 2006;72(4):413-46.

60. Poushter J. Smartphone ownership and internet usage continues to climb in emerging economies. Pew Research Center 2016;22:1-44.

61. Leung L. Net-generation attributes and seductive properties of the internet as predictors of online activities and internet addiction. Cyberpsychol Behav 2004;7(3):333-48.

62. Van Rooij A, Prause N. A critical review of "Internet addiction" criteria with suggestions for the future. J Behav Addict 2014;3(4):203-13.

Acknowledgements - Sincere gratitude to Dr. Anuja Deshpande, Ms. Havovi Hyderabadwalla and Dr. Avinash De Sousa for their relentless mentoring and guidance.

$$
\begin{gathered}
\text { Conflict of Interest - Nil } \\
\text { Funding - Nil }
\end{gathered}
$$

